\title{
Gender and Time Variations in Medical Students' Value Development ${ }^{1}$
}

\author{
Linda Grant ${ }^{2}$ \\ University of Georgia
}

Nancy Genero

The University of Michigan

\section{Paula Nurius}

University of Washington

\section{William E. Moore and Donald R. Brown}

The University of Michigan

A classic study by Becker and Geer proposed that medical students underwent cycles of value development during medical school. Initially, high levels of humanitarianism declined then re-emerged as students neared graduation. Declines in humanitarianism were accompanied by increased interest in extrinsic rewards. This paper examines value development in medical school for 200 men and women recent graduates. Questionnaire data collected at three times were used to develop scales of students' orientations toward humanitarianism and extrinsic rewards. We find partial verification for valuechange patterns described by Becker and Geer, but gender variations are stronger than time variations. Women showed stronger humanitarianism and stronger interest in work conditions at all times than did men. Interest in extrinsic rewards increased for students of both genders but never surpassed humanitarianism in relative importance.

\footnotetext{
${ }^{1}$ The authors appreciate aid in data analysis from Daniel Duross and Tod Sloan and comments on earlier drafts on the paper by Camille Wortman and Roland K. Hawkes. The research was supported partially by a grant from the Spencer Foundation. An earlier version of the paper was presented at the American Sociological Association Meeting in Detroit.

2To whom correspondence should be addressed at Department of Sociology, The University of Georgia, Athens, Georgia 30602.
} 
In a classic paper Becker and Geer (1958) defined cyclical patterns of value development among medical students. These authors' longitudinal, ethnographic study found that students entered medical school with idealistic, humanitarian orientations stressing service to patients. Midway through medical school, students' humanitarianism diminished substantially and they exhibited "detached concern" toward patients (Lief \& Fox, 1963) combined with increased interest in the material and status rewards of physicians' careers. As they neared graduation, however, students' humanitarian orientations increased once more, although their humanitarianism never reached the peaks shown by entering students. Becker and Geer concluded that the cyclical patterns represented in part a necessary corrective to students' naive conceptions about physicians' roles and in part a situational adaptation to competition, heavy work loads, constant fatigue, and other stresses of medical school.

Numerous scholars have verified similar patterns of value change over time in medical students (see, e.g., Broadhead, 1983; Bruhn, 1971; Cliff \& Menzie, 1972; Coombs, 1978; Gordon \& Mensch, 1962; Haas \& Shaffir, 1977; Leserman, 1981; Lerner, 1967; Lief \& Fox, 1963). Similar cycles of declines in humanitarianism and increases in material-rewards interest have been reported for students in dentistry (Eli, 1984) and pharmacy (Chappel \& Barnes, 1983; Hatoum, Smith, \& Sharpe, 1982). A few researchers, however, have found little change over time in medical students' values (Juan et al., 1973) or little increase in humanitarianism as their training progressed (Rosinski, 1963).

Writers have disagreed not only about the types of value alterations that occur in medical school but also about implications of values for physicians' effective functioning and quality of care. While most argue that loss of humanitarianism has deleterious effects on patient care and makes patients reluctant to comply with treatment plans (see DiMatteo \& DiNicola, 1982, for a review), some see a measure of detachment from patients as necessary for the effective performance of the physician's role (Coombs, 1978; Merton et al., 1957; Perricone, 1974; Werner \& Kosch, 1976). Too great an involvement with patients might impair a physician's judgment, or make him or her reluctant to suggest treatments that are painful or uncomfortable. Furthermore, heavy emotional investment with patients may lead to burnout and stress for physicians (Brickman, Karuza, Cohn, Rabinowitz, Coates, \& Kidder, 1982; Freudenberger, 1975; Maslach, 1976, 1979; Maslach \& Pines, 1978). Ironically, the most caring among the helping professionals seem the most vulnerable to burnout and more serious disorders (Brickman et al., 1982).

Most studies of medical students' value development were carried out in an era when women constituted only token minorities in medical classes. 
There has been substantial debate about how the presence of larger proportions of women in medical school will affect students' value development (Leserman, 1981). Do women students enter medical school with value orientations substantially different from male students? If so, do these orientations persist, or are women students pressured to adopt values characteristic of the male-dominated medical profession? Does the presence of greaterthan-token proportions of women in medical classes alter schools' social climates in ways that make all students more supportive of humanitarian values and less attracted to extrinsic rewards of medicine? These questions remain unanswered in current research.

\section{GENDER AND VALUE DEVELOPMENT}

The empirical literature on gender-systematic differences in value orientations of women and men medical students has not been entirely consistent. Some works suggest that while divergences are not wide, women tend to be more humanitarian and less interested in medicine's extrinsic rewards than men. Cartwright (1973), Fruen et al. (1974), and Roessler et al. (1975), for example, report that at various points in training women are more concerned than men with the helping dimensions of medicine. Dickinson and Pearson (1979) found that women desired closer contacts with patients. Funkenstein (1978), Grant and DuRoss (1984), and Kutner and Brogan (1978) report that women, in comparison to men, students rated income and prestige as less important goals of medical careers.

Other studies, however, found little or no differences in women's and men's value orientations (Becker, Katatsky, \& Seidel, 1973; McGrath, 1977). Some scholars argue that proportions of women in a class are critical determinants of whether or not women will exhibit different value orientations toward medical practice (Bluestone, 1978; Walsh, 1977; Wolman \& Frank, 1975). These authors contend that women enter medical school with value orientations substantially different from men's. Only if there is a large enough "critical mass" of women in medical school will these distinctive orientations persist, however. Where women constitute only small minorities of a class, a "masculine" social climate will prevail, and women will be pressured to conform to professional orientations defined primarily by men. Thus, the potential of women to transform medical practice, even if they enter medical school with different value orientations, will be sharply diminished. Women who do not conform to traditional value orientations of physicians will be defined as "unprofessional" and will face limited opportunities for advancement (Lorber, 1984). 
Leserman (1981), one of the few to study women's and men's value development in medical school longitudinally, reports results partially consistent with such a theory. In classes from three medical schools containing from 22 to $29 \%$ women, women entered with values somewhat more humanitarian and less extrinsically reward oriented than male classmates. By their senior year, however, the women's values had become more similar to the men's.

\section{GOALS OF THIS PAPER}

With the exception of Leserman's study, most research on women's and men's value development in medical school has been cross-sectional. Such studies cannot answer questions about whether male-female value differences, if they appear, result from selection or from different patterns of value alterations among women and men during medical school. Such studies also raise questions about stability of patterns across cohorts, and generalizability of findings, to other times and settings (see Roos \& Fish, 1974). Studies also have defined and measured key concepts such as humanitarianism and extrinsic rewards motivation in a multitude of ways, and many have used only single-item measures. Some research on women's orientations has lacked an appropriate comparison group of men (see, e.g., Cartwright, 1973). Because of methods and sample limitations, previous studies have been unable to address several important questions, which are the focus of this paper. These include:

1. Does the pattern of decline then re-emergence of humanitarianism described by Becker and Geer appear for contemporary medical students?

2. Do men and women display distinctive value orientations toward medical practice at the time they enter medical school? More specifically, do women show greater interest in humanitarianism and less interest in the extrinsic rewards of medical practice in comparison to men?

3. If women enter with distinctive value orientations, are these values maintained throughout medical school? Are patterns of change in value orientations during medical school similar or dissimilar for men and women?

4. Are there systematic variations in patterns of value alteration among women and men students that are traceable to varying proportions of men and women enrolled in particular classes and programs?

We define humanitarian orientation as one that places major emphasis on serving patients, alleviating suffering, and meeting patients' medical and 
nonmedical needs as central concerns - what Leuptow (1981) terms "people values." We define extrinsic rewards orientation as one centered on deriving material, status, or prestige rewards from occupying the professional role of physician. While Becker \& Geer (1958) envisioned humanitarian and materialistic orientations as diametrically opposed to one another, more recent empirical studies with pharmacy students suggest that these two value dimensions are independent (Chappell \& Barnes, 1983).

\section{DATA SOURCE AND METHODS}

Women's and men's orientations and motivations for practicing medicine were assessed by analysis of men and women students' responses to self-administered questionnaires. Data were collected three times during medical school at two-year intervals. Respondents were 200 students (130 men and 70 women) enrolled in a large Midwestern medical school, who received M.D. degrees in 1978-1981.

The respondents were almost equally divided between those in an accelerated program $(N=101)$ which enrolled students directly from high school and trained them as physicians in six years and those in a standard pathway $(N=99)$ that admitted students to medical school after they had obtained a bachelor's degree. The two groups took most of their biomedical science courses (equivalent to the first two years of medical school) and all of their clinical rotations together. Women constituted greater proportions of the accelerated program $(39 \%)$ than of the standard program $(25 \%)$ students. Respondents were a population of students graduating from the six-year program in this period, with response rates greater than $95 \%$, and a $22 \%$ random sample of students in the standard program. For comparison purposes, accelerated-program students are treated as a sample.

Only respondents completing questionnaires at all three times were included in the analyses. This resulted in elimination of 26 accelerated program and 29 standard program students. Comparisons of respondents and students who failed to respond at one or more periods showed no systematic variations in demographic and background factors. Students with poor academic records were less likely to have responded at all periods than were those with average or better records. Women and men were equally likely to have responded at all times. Self-administered questionnaires, part of an ongoing evaluation project, collected information about students' personal values, professional orientations, life's priorities, career plans, and issues most important in career choices. All items included in analyses reported here were repeated in each wave of data collection.

Data were collected at three comparable time points for students in each program. Time 1 represented entry into the biomedical sciences curriculum 
of medical school. For standard program students this was the beginning term of medical school. For accelerated program students this was the beginning of the third year in their six-year curriculum, the point at which they had completed liberal arts requirements and joined regular medical students for coursework equivalent to the first medical school year. Time 2 was at the completion of the two-year biomedical coursework for students in both programs. For standard students this was the end of the second year of medical school; for accelerated program students it was the end of the fourth year in their six-year sequence. Time 3 for students in both programs was near the end of the clinical rotations phase of medical education, shortly before the students graduated. Data were combined across cohort within each program after primary analyses revealed no substantial variation by cohort.

Maximum-linkage cluster analyses were used to develop two scales of students' value orientations toward medical careers. One scale measured humanitarian orientations at the three times. The second measured extrinsic rewards orientations. As Leserman (1981) has noted, multiple-item scales provide greater reliability in measurement of value concepts than do single-item measures.

\section{MEASURES}

The Humanitarian Scale (see Table I) is comprised of seven items associated with themes of helping and service, empathy, and working with people. The scale is highly reliable at all three times, with alpha (internal consistency) levels ranging from .78 to .80 .

The Extrinsic Rewards Scale (see Table II) is a five-item scale tapping themes such as interest in income, material goods, respect, leadership, and

Table I. Items Comprising the Humanitarian Orientation Scale ${ }^{a}$

How much importance do you yourself place on the following values?

(1) Helping others

(2) Human respect

(3) Empathy

How much importance did the following have in your decision to seek a career as a physician?

(4) Desire to be of service to mankind

Indicate how much these possible aspects of medicine appeal to you

(5) Opportunity to be helpful to others

(6) Working with people rather than things

How much importance would the following have in your choice of an area of specialization?

(7) The Opportunity it provides for genuine service

${ }^{a}$ Response categories for all items: very much (5), fairly much (4), some (3), very little (2), none (1). Alphas: Time 1\$, .80; Time 2, .78; Time 3, .80. 
Table II. Items Comprising the Extrinsic Rewards Scale ${ }^{a}$

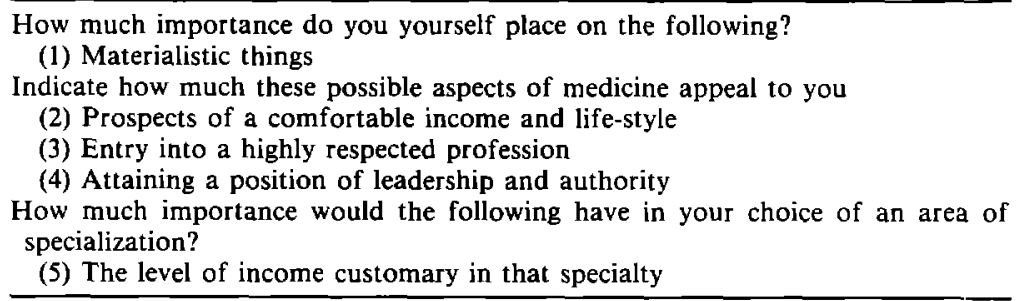

${ }^{a}$ Response categories for all items: very much (5), fairly much (4), some (3), very little (2), none (1). Alphas: Time 1, .83; Time 2, .80; Time 3, .81.

authority as rewards of medical practice. This scale also is highly reliable at all periods, with alpha levels ranging from .80 to .83 .

Profile analyses were used to assess variations over time and by gender in students' mean scores on each scale and differences. Scores on each scale at each time could range from 1 (indicating low humanitarianism or low extrinsic-rewards orientation to 5 (indicating high humanitarianism or high extrinsic rewards orientation). Morrison (1967) provides a description of the use and the interpretation of profile analysis.

\section{RESULTS}

Table III shows zero-order correlations among students' scores on the humanitarianism and extrinsic rewards orientation scales at each datacollection point. The table shows moderate intercorrelations (ranging from .48 to .58) among students' scores on the Humanitarianism Scale across the three times. There also are moderate intercorrelations (ranging from .46 to .69) on students scores on the extrinsic rewards orientation scale across the three times. Negligible to weak negative correlations (ranging from -.03 to -.23 ) appear between students' scores on the Humanitarianism and Extrinsic Rewards scales within and across time periods, suggesting that the two scales are relatively independent of one another.

Table IV shows male and female students' mean scores on each scale at the three times. Scale scores represent the grand mean of students' responses to items comprising each scale. Although scores vary over time, the ordinal ranking of the two value orientations do not change for either women or men. At all periods humanitarianism is more important, and extrinsic rewards orientation less important, for both genders.

In using profile analysis one first tests for parallelism of profiles (Morrison, 1967). Profiles are parallel if there are no significant time-gender 
Table III. Zero-Order Correlations Among Humanitarianism and Extrinsic Rewards Orientation at Three Times

\begin{tabular}{lrrrrrr}
\hline & \multicolumn{5}{c}{ All respondents } \\
\cline { 3 - 6 } & $\mathrm{H}_{1}$ & $\mathrm{H}_{2}$ & $\mathrm{H}_{3}$ & $\mathrm{E}_{1}$ & $\mathrm{E}_{2}$ & $\mathrm{E}_{3}$ \\
\hline $\mathrm{H}_{1}{ }^{a}$ & & & & & & \\
$\mathrm{H}_{2}$ & .513 & & & & \\
$\mathrm{H}_{3}{ }^{b}$ & .480 & .580 & & & \\
$\mathrm{E}_{1}{ }^{b}$ & -.207 & -.029 & -.227 & & \\
$\mathrm{E}_{2}$ & -.166 & -.069 & -.130 & .600 & \\
$\mathrm{E}_{3}$ & -.207 & -.136 & -.140 & .467 & .680 \\
\hline
\end{tabular}

${ }^{a} \mathrm{H}$, Humanitarianism Scale. Subscripts denotes times 1,2 , or 3 .

${ }^{b}$ E, Extrinsic Reward Orientation Scale, Subscripts denotes times 1,2 , or 3 .

interactions, so that scores of women and men change in noncomparable ways at one or more times. If profiles are parallel, and hence patterns of change similar over time for both genders, then one can test for significant differences over time, and across gender and program, in mean scores on a scale.

For both scales, profiles are parallel. On the humanitarianism scale there are significant differences based on students' program of enrollment. On the extrinsic rewards orientation scale there are no differences in response pattern by program, and thus data for students in both programs have been combined for further analysis.

Figure 1 shows plotted means of men and women students on the Humanitarianism Scale at the three times. The profiles for men and for women students show a pattern similar to that reported by Becker and Geer, with one variation. Students enter with relatively high levels of humanitarianism. As Becker and Geer found, humanitarianism declines at Time 2, the end of the second medical school year. Nevertheless, among these students humanitarianism is slightly higher when they are ready to leave medical school than when they entered. However, as the statistic for the test of equality of variable means indicates, these time variations do not reach statistical signifcance. At their lowest point students' levels of

Table IV. Male and Female Medical Students' Mean Orientations on Humanitarianism and Intrinsic Reward Scales ${ }^{\alpha}$ at Three Points in Time

\begin{tabular}{|c|c|c|c|c|c|c|}
\hline & \multicolumn{2}{|c|}{ Time 1} & \multicolumn{2}{|c|}{ Time 2} & \multicolumn{2}{|c|}{ Time 3} \\
\hline & Males & $\overline{\text { Females }}$ & $\overline{\text { Males }}$ & Females & Males & Females \\
\hline Humanitarianism & 4.33 & 4.54 & 4.32 & 4.45 & 4.35 & 4.56 \\
\hline Extrinsic rewards & 2.95 & 2.80 & 3.13 & 3.00 & 3.23 & 3.08 \\
\hline
\end{tabular}

${ }^{a}$ Scaled from 5 (high) to 1 (low). Means are calculated as the grand mean of all items comprising the scale. 
humanitarianism are high, never falling below a mean of 4.32 , indicating strong agreement or agreement with most items comprising the Humanitarianism scale.

There are, however, statistically significant gender and program differences in students' orientations on the Humanitarianism scale at all times. Women average consistently higher levels of humanitarism than do the men. As Fig. 1 shows, women's mean levels of humanitarism at their lowest point are still higher than men's mean levels of humanitarism at their highest point. The figure also reveals program of enrollment and gender effects on students' orientations on humanitarianism at the three points. Women in the accelerated program are higher on humanitarism at all times than are women in the standard or males in either program. Males in the two programs are more similar in their orientations than are the females, although the standard program males show greater change in their levels of humanitarianism over time than the males in the accelerated program.

Figure 2 shows profiles for students on the extrinsic rewards orientation scale. Data for students in both programs have been combined in Fig. 2 because there are no significant variations by program. The first point worthy of note is the mean scores of men and women at all times on this

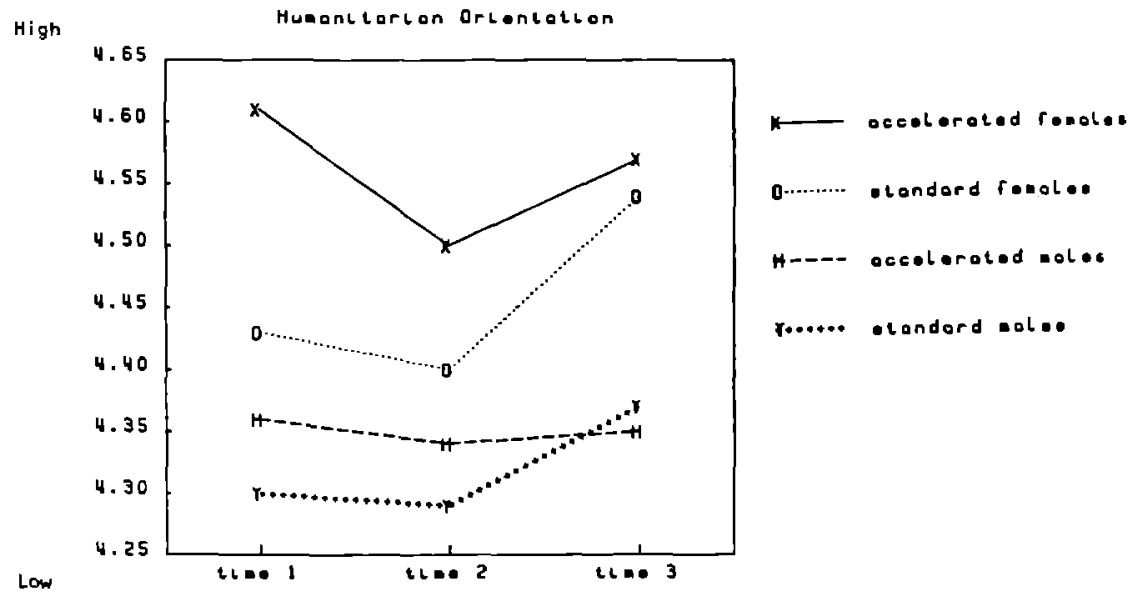

Fig. 1. Mean scores (calculated as the grand mean of all items comprising the scale, coded 1 $=$ low orientation to $5=$ high orientation) on Humanitarian Orientation Scale of men and women medical students in two programs at three time periods during medical school training.

\begin{tabular}{lccc} 
Test for parallelism & \multicolumn{1}{c}{$F$} & $p$ \\
$\begin{array}{l}\text { Test for no difference } \\
\text { over time }\end{array}$ & $\max$ root $=.010150$ & .9500 \\
$\begin{array}{l}\text { Test for no gender } \\
\text { difference }\end{array}$ & 2.0781 & $(2,195)$ & .1279 \\
& 4.0755 & $(3,196)$ & .0078
\end{tabular}




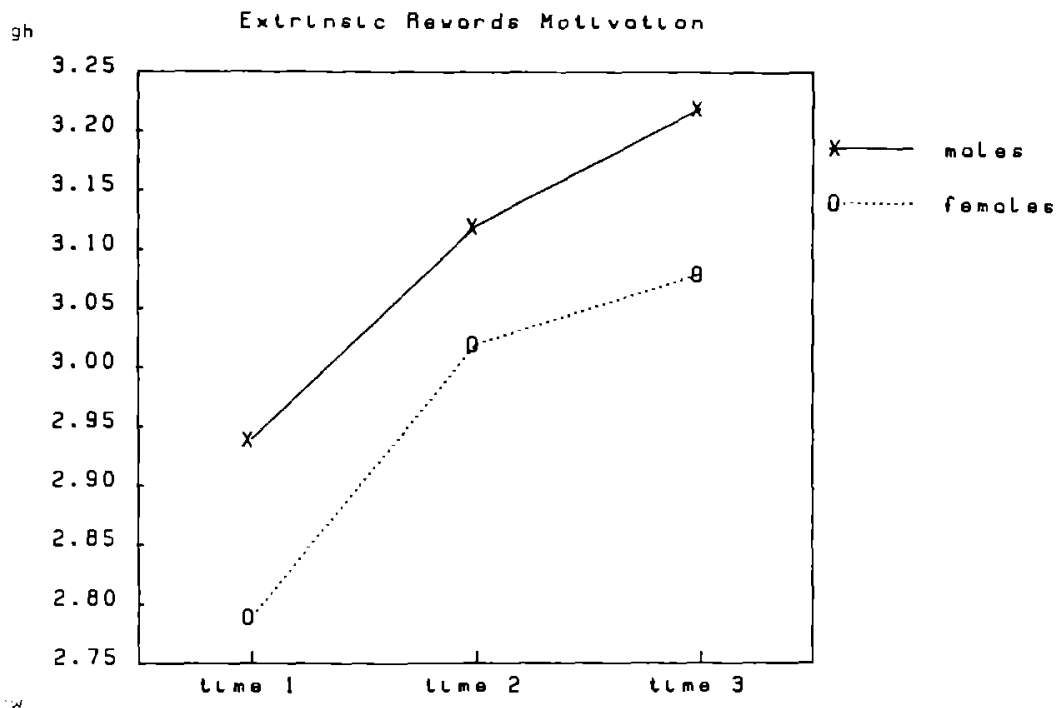

Fig. 2. Mean scores (calculated as grant mean of responses to all items comprising the scale, coded 1 = low orientation to 5 = high orientation) on the Extrinsic Rewards Scale of mean and women medical students at three time periods during medical school.

$\begin{array}{lcc} & F & p \\ \begin{array}{l}\text { Test for parallelism } \\ \text { Test for no differences } \\ \text { over time }\end{array} & .236(2,197) & .790 \\ \begin{array}{l}\text { Test for no gender } \\ \text { differences }\end{array} & 19.113 \quad(2,197) & .0001 \\ & 3.210 \quad(1,198) & .0744\end{array}$

scale as compared to the Humanitarianism Scale. At all periods men and women students are, on the average, less interested in extrinsic rewards than they are in humanitarianism. Nevertheless, there are significant differences across time and across gender (but no significant time-gender interactions) in students' extrinsic rewards motivations. The profiles show significant increases over time in students' valuation of the extrinsic rewards of medical practice. The largest change occurs between entry into medical school and the end of the second year. As shown by the test for equality of variable means reported in Fig. 2, these differences are significant at the $p<.001$ level. There also are marginally significant $(p<.07)$ gender differences in students' mean rankings on the Extrinsic Rewards Scale. Men outrank women at all times in their evaluations of the importance of extrinsic rewards of medical practice.

\section{DISCUSSION}

Our findings provide only partial verification of hypotheses advanced by Becker and Geer (1958) about students' value development during medical 
school. Our study also suggests that, despite similarity in patterns of value change for women and men, women enter and leave medical school with slightly stronger humanitarian orientations than male classmates.

Although the decline and subsequent re-emergence of humanitarianism described by Becker and Geer is discernible in our study, declines in humanitarianism midway maintain strong humanitarian orientations throughout students' medical education and consistently rate this value as more important than extrinsic rewards. It is possible that Becker and Geer overestimated the magnitude of declines in humanitarianism, or that these declines are less severe among contemporary students than they were among students of the 1950s. It is also possible that those authors, or we, studied students or programs atypical of most American medical schools. More research on this issue among contemporary students will help clarify this point.

Consistent with Becker and Geer's hypothesis, we find that students increase their interest in material rewards over time in medical school. Contrary to Becker and Geer's argument, however, these increases do not appear to come at the expense of humanitarian orientations. Our findings for students of both genders are consistent with Becker and Geer's argument that the medical school environment enhances interest in material rewards, but do not support their contention that for most students such rewards become more central than humanitarian values. Students in our study apparently reconciled without contradiction increased interest in extrinsic rewards with caring, people-oriented values. The two value dimensions appeared to be relatively independent of one another, consistent with findings of Chappell and Barnes (1983). A reconceptualization of the interrelationships among these two value dimensions is seemingly in order.

Alternatively, it is possible that variations in methods contributed to divergent findings. We examined professed values at an abstract, global level, while Becker and Geer used qualitative methods to examine values in contextspecific situations. Had we measured our two value dimensions at a more specific level, a different pattern of interrelationships might have emerged. This issue also deserves greater attention in future research.

Although patterns of value persistence and change are similar for women and men, women begin and complete their medical training with slightly higher levels of humanitarianism than do men. Women also tend toward less interest in extrinsic reward in comparison to men, but this difference does not quite reach statistical significance at the .05 level. It is uncertain whether or not these gender differences in orientations will persist to the point when students begin practice. Given the small magnitude of gender differences, we would anticipate only minor differences in practice behaviors of women and men physicians. Women might exhibit slightly greater humanitarianism and slightly less concern with extrinsic rewards but would not differ dramatically from their male peers. Whether or not value orientations are 
good predictors of practice behaviors is a still-unresolved question. Several authors (e.g., Bosk, 1979; Bucher \& Stelling, 1977; Mumford, 1970; Wheeler, 1966) suggest that internship, residency, or the early-career years are more important than medical school for establishing core values that affect practice style and career choice. Others (e.g., Friedson, 1970; Lorber, 1984) suggest that structural aspects of practice settings and situational contingencies are more important than physicians' values in influencing practice behaviors.

Our findings are less conclusive in relation to our fourth question concerning effects of proportions of students in a class. Although women in the accelerated program, with a $\mathbf{4 0 \%}$ female enrollment, showed higher levels of humanitarianism than other student groups at all periods, our data do not permit us to determine clearly whether this resulted from a selection or a socialization effect. Although statistically significant, these variations also were small in magnitude. The accelerated-program women had higher levels of humanitarianism at entry, evidence favoring a selection effect. Also, men in this program were lower in humanitarianism than standard-program women and similar to standard-program men. Had the accelerated program's internal climate exerted strong pressure supporting humanitarian orientations, we would expect to see a stronger impact on men's as well as women's values. However, it is also possible that an internal climate supportive of humanitarianism had marginally stronger effects for the women than for the men. Other aspects of the accelerated program might also have contributed to stronger humanitarianism among its students, especially the women. Accelerated students bypassed traditional premedical education, which some writers view as more competitive and dehumanizing than the medical school experience (Broadhead, 1983; Coombs, 1978).

Another plausible interaction is that the proportions of women present in both programs, and the more humanistic orientations they possessed in comparison to the men, minimized the decline in humanitarianism midway through medical school for all students. Even the $25 \%$ women present in the standard program might have constituted a substantial enough minority to produce such an effect. Separation of proportions-of-women effects from program-selection effects is a complex question and can be answered only by longitudinal analysis, and comparisons of schools and classes with wider variations in proportions of women students.

Our findings do suggest that increasing proportions of women entering the medical profession might bring increased commitment to humanitarian values, at least through medical school graduation. The increase is a modest rather than a dramatic one, however. An important next step for researchers is determining whether or not women's distinctive orientations survive postsecondary medical education and affect the practice of medicine in social- 
ly desirable ways. Another important question, beyond the scope of this paper, is the possible link between humanitarian orientations and burnout, and other negative outcomes for helping professionals. It is possible that women's somewhat greater humanitarianism will pose risks for their own well-being. Lorber (1984) suggests that one reason displays of caring becomes stressful for women physicians is that such behaviors are interpreted as deviant and unprofessional. If women can successfully alter normative aspects of physicians' roles, making displays of caring positively rather than negatively valued, such stress might be substantially reduced. The discovery of ways to tap physicians' humanitarianism in socially beneficial ways without posing excessive risk to these doctors' well-being is a critical issue for researcher, medical educators, and health policy planners.

\section{REFERENCES}

Becker, H., \& Geer, B. The fate of idealism in medical school. American Sociological Review, $1958,23,50-56$.

Becker, M., Katatsky, M., \& Seidel, H. A follow-up study of unsuccessful applicants to medical school. Journal of Medical Education, 1973, 48, 991-1001.

Bluestone, N. The impact of women physicians on American medicine. American Journal of Public Health, 1978, 68, 760-762.

Bosk, C. Forgive and remember: Managing medical failure. Chicago: University of Chicago Press, 1979.

Brickman, P., Karuza, E., Cohn, E., Rabinowitz, V., Coates, D., \& Kidder, L. Models of helping and coping. American Psychologists, 1982, 37, 368-384.

Broadhead, R. The Private lives and professional identity of medical students. New Brunswick, N.J.: Transaction Book, 1983.

Bruhn, J. On social responsibility. Journal of Medical Education, 1971, 46, 368-384.

Bucher, R., \& Stelling, J. Becoming professional. Beverly Hills, Calif.: Sage Publications, 1977.

Cartwright, L. Conscious factors entering in the decision of women to study medicine. Journal of Social Issues, 1973, 28, 201-215.

Chappell, N., \& Barnes, G. Professional and business role orientations among practicing pharmacists. Social Science and Medicine, 1983, 18, 103-110.

Cliff, M., \& Menzie, C. Attitudes of medical students toward medical school and future careers. Journal of Medical Education, 1972, 47, 534-538.

Coombs, R. Mastering medicine: Professional socialization in medical school. New York: The Free Press, 1978.

Dickinson, G., \& Pearson, A. Sex differences of physicians in relating to dying patients. Journal of the American Medical Women's Association, 1979, 34, 45-47.

DiMatteo, R., \& DiNicola, D. Achieving patient compliance: The psychology of the medical practitioner's role. New York: Pergamon, 1982.

Eli, I. Professional socialization in dentistry: A longitudinal analysis of change in students' expected professional rewards. Social Science and Medicine, 1984, 18, 297-302.

Freudenberger, H. The staff burnout syndrome. Washington, D.C.: The Drug Abuse Council, 1975 .

Friedson, E. Profession of medicine: A study of the sociology of applied knowledge. New York: Dodd, Mead, 1970.

Fruen, M. A., Rothman, A. I., \& Steiner, J. W. Comparisons of characteristics of male and female medical school applicants. Journal of Medical Education, 1974, 49, 135-145. 
Funkenstein, D. Medical students, medical schools, and society during given eras: Factors affecting the career choices of physicians 1958-1976. Cambridge, Mass.: Ballinger, 1978.

Gordon, J., \& Mensch, I. Values of medical students at different levels of training. Journal of Health and Human Behovior. 1962, 7, 128-132.

Grant, L., \& DuRoss, D. Expected rewards of practice and personal life priorities of women and men medical students. Sociological Focus, 1984, 17, 87-104.

Haas, J., \& Shaffir, W. The professionalization of medical students: Developing competence and a cloak of competence. Symbolic Interactionism, 1977, 1, 71-88.

Hatoum, H., Smith, M., \& Sharpe, T. Attitudes of pharmacy students towards psychosocial factors in health care. Social Science and Medicine, 1982, 16, 1239-1241.

Juan, I. R., Paiva, R. E., Haley, H. B., \& O'Keefe, R. The relationship between career choice and some aspects of information seeking styles among students. In Proceedings of the Twelfth Annual Conference on Research in Medical Education. Washington, D.C., 1973.

Kutner, N., \& Brogan, D. The decision to enter medicine: Motivations, social support, and discouragements for women. Psychology of Women Quarterly, 1978, 5, 341-358.

Lerner, M. Changes in medical students during the course of medical education. Journal of Medical Education, 1967, 42, 272-283.

Leserman, J. Men and women in medical school: How they change and how they compare. New York: Praeger, 1981.

Lief, H., \& Fox, R. The medical student's training for “detached concern” In H. Lief \& N. Lief (Eds.), The psychological basis of medical practice. New York: Harper \& Row, 1963.

Lorber, J. Women physicians: Careers, status, and power. New York and London: Tavistock, 1984.

Leuptow, L. Sex-typing and change in the occupational choices of high school seniors, 1965-75. Sociology of Education, 1981, 54, 16-24.

Maslach, C. Burned-out. Human Behavior, September, 1976, 16-22.

Maslach, C. The burnout syndrome and patient care. In C. Garfield (Ed.), Stress and survival. St. Louis: Mostsy, 1979.

Maslach, C., \& Pines, A. Burnout. The loss of human caring. In A. Pines and C. Maslach (Eds.), Experiencing social psychology. New York: Knopf, 1978.

McGrath, E., \& Zimet, C. Female and male medical students: Differences in specialty choice selection and personality. Journal of Medical Education, 1977, 52, 293-300.

Merton, R. K., Reader, G. G., \& Kendall, P. (Eds.). The student physician. Cambridge, Mass.: Harvard University Press, 1957.

Morrison, D. Multivariate statistical methods. New York: McGraw-Hill, 1967.

Mumford, E. From siudents to physicians. Cambridge, Mass.: Harvard University Press, 1970.

Perricone, P. Social concern in medical students: A reconsideration of the Eron assumption. Journal of Medical Education, 1974, 42, 770-774.

Roessler, E., Collins, F., \& Mefferd, R. Sex similarities in successful medical school applicants. Journal of the American Medical Women's Association, 1975, 30, 254-265.

Roos, N., \& Fish, D. Change in career preferences: Students as a group vs. students as individuals. Journal of Medical Education, 1974, 49, $1057-1059$.

Rosinski, E. Professional, ethical, and intellectual attitudes of medical students. Journal of Medical Education, 1963, 38, 1016-1022.

Walsh, M. Doctors wanted: No women need apply: Sexual barriers in the medical profession. New Haven, Conn.: Yale University Press, 1977.

Werner, E., \& Kosch, B. The vulnerability of medical students: Posthumous presentation of L. L. Stephen's ideas. Pediatrics, 1976, 52, 321-328.

Wheeler, S. The structure of formally organized socialization settings. In O. G. Brim \& S. Wheeler (Eds.), Socialization after childhood: Two essays. New York: John Wiley \& Sons, 1966.

Wolman, C., \& Frank, H. The solo woman in the peer professional group. Journal of Orthopsychiatry, 1975, 45, 164-171. 